\title{
Nano-ilmenite $\mathrm{FeTiO}_{3}$ : Synthesis and characterization
}

\author{
A.T. Raghavender ${ }^{\mathrm{a}, *}$, Nguyen Hoa Hong $^{\mathrm{a}}$, Kyu Joon Lee ${ }^{\mathrm{b}}$, Myung-Hwa Jung $^{\mathrm{b}}, \mathrm{Z}$. Skoko ${ }^{\mathrm{c}}$, M. Vasilevskiy ${ }^{\mathrm{d}}$, \\ M.F. Cerqueira ${ }^{\mathrm{d}}$, A.P. Samantilleke ${ }^{\mathrm{d}}$ \\ a Nanomagnetism Laboratory, Department of Physics and Astronomy, Seoul National University, Seoul 151-747, South Korea \\ b Department of Physics, Sogang University, 1 Shinsu-dong, Mapo-gu, Seoul 121-742, South Korea \\ ${ }^{c}$ Department of Physics, Faculty of Science, University of Zagreb, Bijenicka C. 32, HR-10000, Zagreb, Croatia \\ d Centro de Física, Universidade do Minho, Braga 4710-057, Portugal
}

\section{A R T I C L E I N F O}

\section{Article history:}

Received 29 March 2012

Received in revised form

10 September 2012

Available online 23 November 2012

Keywords:

Nano-Ilmenite

Structural

Optical

Magnetic properties

\begin{abstract}
A B S T R A C T
In general, ilmenite $\mathrm{FeTiO}_{3}$ is synthesized by solid-state reaction at very high pressure and high temperature. Synthesis of $\mathrm{FeTiO}_{3}$ is not an easy task as the $\mathrm{Fe}^{2+}$ ions are not stable. Therefore, it is really challenging to prepare this material. In this work nano-ilmenite $\mathrm{FeTiO}_{3}$ was synthesized by the sol-gel method. Structural, optical and magnetic characterizations were performed. The bandgap of $\mathrm{FeTiO}_{3}$ was determined to be $2.8 \mathrm{eV}$ showing $\mathrm{FeTiO}_{3}$ as suitable wide bandgap material for technological applications. The $\mathrm{FeTiO}_{3}$ nanoparticles exhibit weak ferromagnetic properties at and below room temperature. The Néel temperature was observed to be around $52 \mathrm{~K}$.
\end{abstract}

(c) 2012 Elsevier B.V. All rights reserved.

\section{Introduction}

Ilmenite $\mathrm{FeTiO}_{3}$ is antiferromagnetic (AFM) and insulting but the intermediate compositions can be semiconducting and insulating [1-6]. $\mathrm{FeTiO}_{3}$ is one of the most common mineral in the Earth crust [7]. $\mathrm{FeTiO}_{3}$ is an interesting wide bandgap (2.58$2.9 \mathrm{eV}$ ) antiferromagnetic semiconductor [8,9] with potential applications in spintronics, optoelectronics, high temperature integrated circuits, chemical catalysts and photocatalysts etc. [10-13]. Most of the efforts have been devoted for designing ferromagnetic semiconductors operating at room temperature on homogeneous doping of semiconductors with magnetic impurities [14-16]. Furthermore, since the conductivity type ( $p$ or $n$ ) can be tuned by changing the doping density of $\mathrm{Ti}$ into hematite promises additional applications in electronic devices such as low-voltage varistors [17]. Ilmenite has rhombohedral structure with space group $R \overline{3}$ and the Néel temperature is around $55 \mathrm{~K}$ [3]. In $\mathrm{FeTiO}_{3}, \mathrm{Fe}$ and $\mathrm{Ti}$ layers are arranged alternate, this reduces the symmetry to $R \overline{3}$ with AFM coupling between the Fe layers with $T_{N}=56-59 \mathrm{~K}[18,19]$. Fujii et al. [20] have reported that $\mathrm{FeTiO}_{3}$ thin films with $R \overline{3}$ symmetry were ferrimagnetic at lower temperature, while $\mathrm{R} \overline{\mathrm{C}} \mathrm{C}$ symmetry was antiferromagnetic. Assuming that $\mathrm{Ti}^{4+}$ is in $\mathrm{B}$ site and $\mathrm{Fe}^{3+}$ is equally distributed between $\mathrm{A}$

\footnotetext{
* Corresponding author. Tel.: +822880 6603; fax: +82 28843002.

E-mail addresses: atraghavender@snu.ac.kr, raghavi9@gmail.com (A.T. Raghavender).
}

and $\mathrm{B}$ sites, the chemical composition can be written as

$$
\left(\mathrm{Fe}_{x}^{2+}, \mathrm{Fe}_{1-x}^{3+}\right)_{A-s i t e}\left(\mathrm{Ti}_{x}^{4+}, \mathrm{Fe}_{1-x}^{3+}\right)_{B-\text { site }} \mathrm{O}_{3}
$$

It was reported that $\mathrm{FeTiO}_{3}$ could be synthesized by using solid-state reaction above $1200^{\circ} \mathrm{C}$ under vacuum [21-23]. Popular techniques that have been employed to synthesize $\mathrm{FeTiO}_{3}$ in the recent year include ball milling [24], chemical reduction techniques [11], co-precipitation [25] etc. The structural, optical, electrical and magnetic properties of $\mathrm{FeTiO}_{3}$ are strongly influenced by the preparation technique [26]. It is also observed that the synthesis of $\mathrm{FeTiO}_{3}$ is made complicated by the instability of $\mathrm{Fe}^{2+}$ in $\mathrm{FeTiO}_{3}$. In this work, we have successfully synthesized nano-ilmenite $\mathrm{FeTiO}_{3}$. In addition the magnetic, structural and optical properties of nano-ilmenite were characterized.

\section{Experiment}

Nano-ilmenite $\mathrm{FeTiO}_{3}$ has been synthesized by using the sol-gel auto-ignition method [27]. The A.R grade citric acid $\left(\mathrm{C}_{6} \mathrm{H}_{8} \mathrm{O}_{7} \cdot \mathrm{H}_{2} \mathrm{O}\right)$, ferric (III) nitrate nonahydrate $\left(\mathrm{Fe}\left(\mathrm{NO}_{3}\right)_{3} \cdot 9 \mathrm{H}_{2} \mathrm{O}\right)$, titanium dioxide $\left(\mathrm{TiO}_{2}\right)$ ( $\geq 99.99 \%$ ) from Sigma-Aldrich were used as precursor materials. The molar ratio of metal nitrates to citric acid was taken as $1: 3$. Titanium nitrate was made by converting, titanium dioxide by dissolving in nitric acid. Ferric nitrate and citric acid were dissolved in minimum amount of de-ionized water to obtain a clear solution. The resulting two solutions were mixed together and stirred for about $30 \mathrm{~min}$ to get a uniform mixture solution. The $\mathrm{pH}$ was adjusted to 7 using ammonia; the 
temperature of the solution was increased to $200{ }^{\circ} \mathrm{C}$. After $4-5 \mathrm{~h}$, the water molecules evaporated from the chemical solution. During evaporation, the solution became viscous and finally formed a very viscous brown/black gel. When all the remaining water was released from the mixture, the sticky mass began to bubble. During this time the temperature of the beaker was increased to $380^{\circ} \mathrm{C}$ in order to increase the reaction rate. After several minutes, the gel automatically ignited and burnt with glowing flints. The decomposition reaction would not stop before the whole citrate complex was consumed. The auto-ignition was completed within a minute yielding the brown-colored ashes. The as-prepared powder sample was annealed at $500{ }^{\circ} \mathrm{C}$ for $10 \mathrm{~h}$ to get the final product. For transmission measurements, a thin layer of $\mathrm{FeTiO}_{3}$ was coated on fluorine doped tin oxide (FTO) glass electrode using the doctor blade method [28]. For Raman measurements, $\mathrm{FeTiO}_{3}$ powder was then pressed into pellets of diameter $10 \mathrm{~mm}$ and thickness $4 \mathrm{~mm}$ at a pressure of $40 \mathrm{MPa}$. The obtained pellets were sintered in air at $500{ }^{\circ} \mathrm{C}$ for $10 \mathrm{~h}$.

The microstructure of the $\mathrm{FeTiO}_{3}$ was studied by Raman scattering. Micro-Raman spectra have been measured in a frequency range of $50-750 \mathrm{~cm}^{-1}$, using the $488 \mathrm{~nm}$ excitation line of an $\mathrm{Ar}^{+}$laser, in the back scattering geometry, on a Jobin-Yvon T64000 spectrometer equipped with a liquid nitrogen cooled CCD detector. In order to avoid sample heating the incident sample laser power has been kept at $4 \mathrm{~mW}$. The thicknesses of the films were measured using VEECO Dektak 150 surface profiler. The grain size and morphology were verified by using Hitachi SU-70, high resolution scanning electron microscope (HR-SEM) with an energy dispersive X-ray spectrometer (EDS) installed. EDS was performed to further confirm the composition of the prepared samples. The magnetization was measured by a commercial MPMS (Quantum Design) superconducting quantum interference device (SQUID) magnetometer in applied fields up to $70 \mathrm{kOe}$ and in the temperature range of $5-300 \mathrm{~K}$.

\section{Results and discussions}

It is well known that the positions and widths of Raman bands of materials are related to their vibrational and structural properties. According to literature, the Raman peaks of $\mathrm{FeTiO}_{3}$, in the studied range, are at 220, 250,300,410,509, 610 and $650 \mathrm{~cm}^{-1}$. For the standard $\mathrm{FeTiO}_{3}$, the most intense mode should be $410 \mathrm{~cm}^{-1}$. Fig. 1 shows the Raman spectra of $\mathrm{FeTiO}_{3}$ sample and Table 1 shows the result of the Raman fitting using Lorentzian functions for each band. Thus, we could get the wavenumber and the full-width at halfmaximum (FWHM) of each mode. This sample shows the usual bands related with vibration modes of bonds related with $\mathrm{FeTiO}_{3}$ (mentioned in the literature between 200 and $800 \mathrm{~cm}^{-1}$ ). According to Olivares et al. [29], the produced material is mainly based on iron oxide compounds as $\alpha-\mathrm{Fe}_{2} \mathrm{O}_{3}$ (hematite: $226,296,410,617 \mathrm{~cm}^{-1}$ ) and $\gamma-\mathrm{Fe}_{2} \mathrm{O}_{3}$ (maghemite: $667 \mathrm{~cm}^{-1}$ ), as can be seen by the presence of the modes slightly shifted at 224, 336, 443, 612 (hematite) and $662 \mathrm{~cm}^{-1}$ (maghemite) in the Raman spectra shown in Fig. 1. The presence of iron oxides, such as magnetite indicates a reducing atmosphere, and the observed iron oxides reddish, such as hematite, means that an oxidizing environment was used [30]. The Raman analysis observed for our nano-ilmenite samples are very well in agreement with Sharma et al. [31].

The morphology of $\mathrm{FeTiO}_{3}$ was determined by HR-SEM. Fig. 2 represents the HR-SEM image of $\mathrm{FeTiO}_{3}$ showing a uniform and a narrow distribution of the particles. EDS was performed to further confirm the compositions of the prepared samples. Fig. 3 shows that the prepared $\mathrm{FeTiO}_{3}$ sample consists of $\mathrm{Fe}$, Ti and $\mathrm{O}$. The weight and atomic fractions of all elementary constituents in the synthesized $\mathrm{FeTiO}_{3}$ nanoparticles determined by EDS are presented in Table 2 .

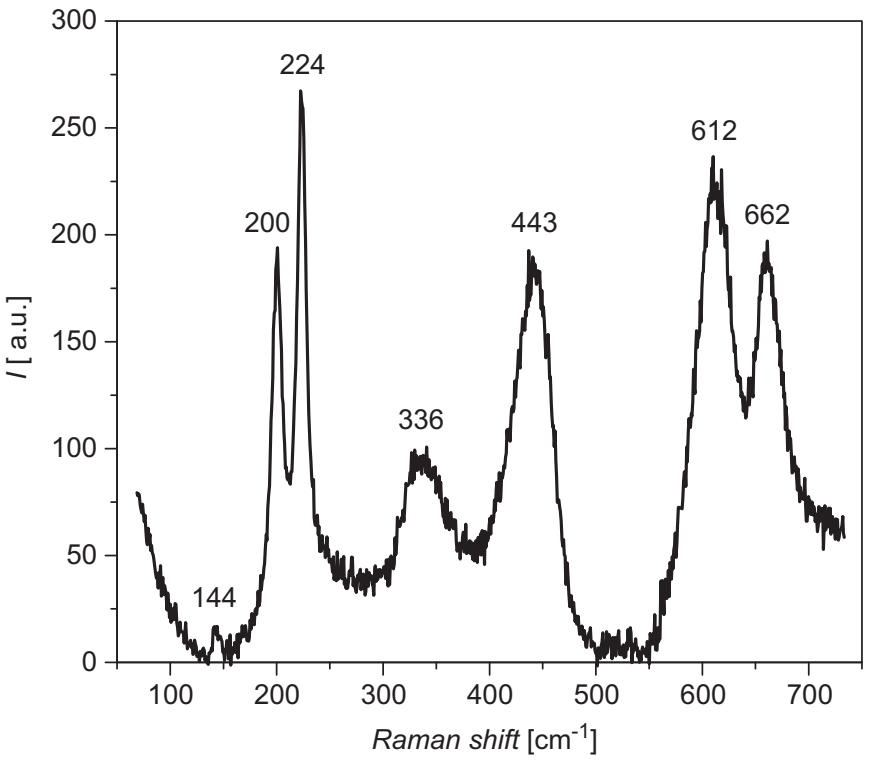

Fig. 1. Room temperature Raman spectra of nanocrystalline $\mathrm{FeTiO}_{3}$.

Fig. 4 shows the transmission spectrum of a typical $\mathrm{FeTiO}_{3}$ nanoparticles coated FTO glass electrode with a film thickness of $1200 \mathrm{~nm}$. The transmission is below $50 \%$ for most of the spectrum mainly due to the large thickness of the sample. However, the transmission is particularly weak in the visible part of the solar spectrum. This may be ascribed to the presence of high molar ratio of $\mathrm{Fe}$ atoms in the lattice of $\mathrm{TiO}_{2}$, resulting in increased visible light absorption. The optical bandgap $E_{g}$ is determined from the extrapolated Tauc plot (Fig. 5) made by using the transmission spectrum. The estimated bandgap for the nanocrystalline $\mathrm{FeTiO}_{3}$ from the Tauc plot (Fig. 5) was approximately $2.80 \mathrm{eV}$, which is comparable with reported bandgap values for antiferromagnetic $\mathrm{FeTiO}_{3}(2.58-2.9 \mathrm{eV})$ elsewhere [32-34].

The $\mathrm{M}-\mathrm{H}$ loops for $\mathrm{FeTiO}_{3}$ were measured at different temperatures as of $10 \mathrm{~K}, 100 \mathrm{~K}$ and $300 \mathrm{~K}$ with an applied field between -70 and 70 kOe are shown in Fig. 6. The inset of Fig. 6 shows the expanded $\mathrm{M}-\mathrm{H}$ at lower scale showing a small nonlinear behavior. At $10 \mathrm{~K}$, the sample shows large coercivity of $818 \mathrm{Oe}$, and at $100 \mathrm{~K}$ and $300 \mathrm{~K}$ with $16 \mathrm{Oe}$ and $12 \mathrm{Oe}$. It is also observed that $\mathrm{M}-\mathrm{H}$ loops do not saturate even up to $70 \mathrm{kOe}$ magnetic field due to paramagnetic or antiferromagnetic nature of the material [34,35]. The remanence magnetization measured for $\mathrm{FeTiO}_{3}$ at different temperatures was considerably small. This kind of magnetic behavior is attributed due to the presence of surface defects/ unsatisfied surface spins that develop in the crystal during the crystallization process [36]. Even though the $M_{r}$ and $H_{c}$ observed in our samples are very small they still show a decreasing trend with increasing temperature. This might be due to the flux trapped by the defects in nano-ilmenite $\mathrm{FeTiO}_{3}$ that gets excluded as the temperature increases [37].

Fig. 7 shows the zero-field-cooled (ZFC) and field-cooled (FC) magnetization curves measured with applied fields $100 \mathrm{Oe}, 500 \mathrm{Oe}$ and 1000 Oe. As the temperature increases the magnetic moment in the FC curve decreases. However, as the temperature begins to increase from $2 \mathrm{~K}$, the magnetic moment in the ZFC curves also decrease up to $45 \mathrm{~K}$ and beyond this point, ZFC curves reach a maximum position at $52 \mathrm{~K}$ and thereafter $\mathrm{FC}$ and ZFC merge together and then steadily decrease up to $300 \mathrm{~K}$. The peak position at $52 \mathrm{~K}$ is assigned to be the Néel temperature of $\mathrm{FeTiO}_{3}$. The FC-ZFC diverges below the $T_{N} \approx 52 \mathrm{~K}$ which agrees with the magnetic transition temperature of $\mathrm{FeTiO}_{3}$. One can clearly see that all the 
Table 1

Wavenumber and FWHM of the $\mathrm{FeTiO}_{3}$ Raman modes.

\begin{tabular}{|c|c|c|c|c|c|c|c|}
\hline Sample & $\omega\left(\mathrm{cm}^{-1}\right) / \Gamma\left(\mathrm{cm}^{-1}\right)$ & $\omega\left(\mathrm{cm}^{-1}\right) / \Gamma\left(\mathrm{cm}^{-1}\right)$ & $\omega\left(\mathrm{cm}^{-1}\right) / \Gamma\left(\mathrm{cm}^{-1}\right)$ & $\omega\left(\mathrm{cm}^{-1}\right) / \Gamma\left(\mathrm{cm}^{-1}\right)$ & $\omega\left(\mathrm{cm}^{-1}\right) / \Gamma\left(\mathrm{cm}^{-1}\right)$ & $\omega\left(\mathrm{cm}^{-1}\right) / \Gamma\left(\mathrm{cm}^{-1}\right)$ & $\omega\left(\mathrm{cm}^{-1}\right) / \Gamma\left(\mathrm{cm}^{-1}\right)$ \\
\hline $\mathrm{FeTiO}_{3}$ & $144 / 12$ & $200 / 12$ & $224 / 11$ & $336 / 60$ & $443 / 50$ & $612 / 50$ & $662 / 40$ \\
\hline
\end{tabular}

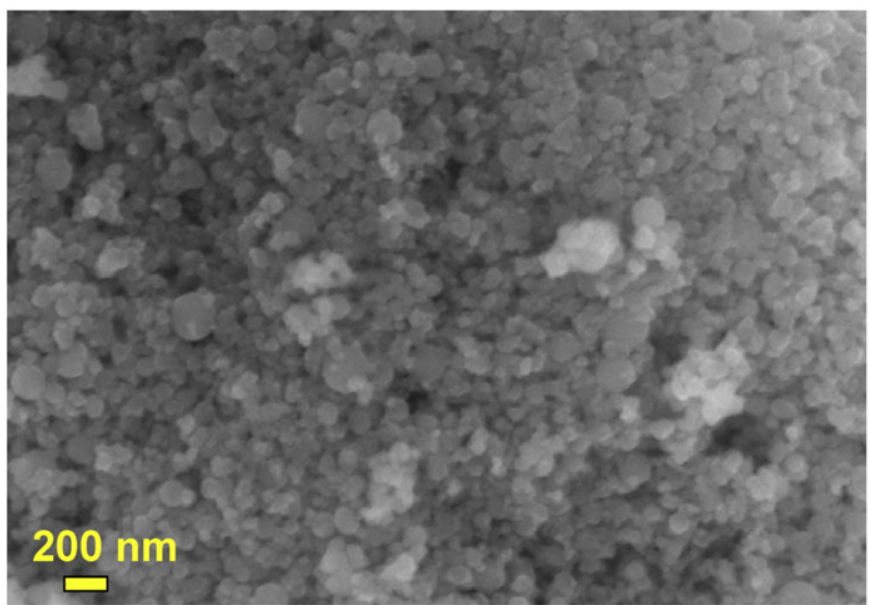

Fig. 2. SEM image of nanocrystalline $\mathrm{FeTiO}_{3}$ powder.

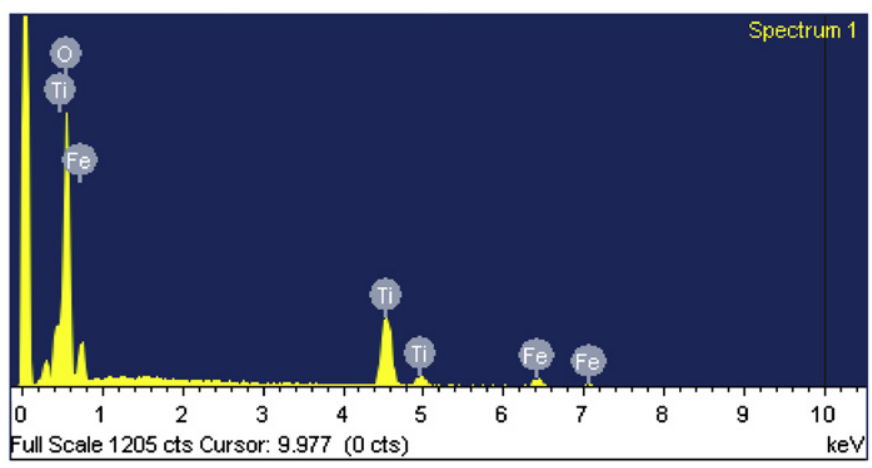

Fig. 3. EDS of nanocrystalline $\mathrm{FeTiO}_{3}$ powder.

Table 2

The elementary constituents of $\mathrm{FeTiO}_{3}$ powder measured by EDS.

\begin{tabular}{lllll}
\hline Elements & $\mathrm{O}$ & $\mathrm{Ti}$ & $\mathrm{Fe}$ & Total \\
\hline Weight percentage (\%) & 36.45 & 28.24 & 35.31 & 100 \\
Atomic percentage (\%) & 62.08 & 16.84 & 18.06 & 100 \\
\hline
\end{tabular}

ZFC and FC curves show similar tendencies. The peak in the ZFC curves corresponds to the Neel temperature [38]. Both FC and ZFC curves resemble those reported in Refs. [18,39]. Above $T_{N}=52 \mathrm{~K}$, Ilmenite is paramagnetic, while below $T_{N}$ the $\mathrm{Fe}^{2+}$ layers couple antiferromagnetically and are separated magnetically inert $\mathrm{Ti}^{4+}$ layers [40]. The peak positions of ZFC and FC (Fig. 7) which are almost independent of the applied fields further confirm the AFM phase transition. Such kind of behavior was observed previously for $\mathrm{CoO}_{3}$ nanoparticles [41]. These unusual magnetic properties were observed from the temperature dependence of the resistivity, magneto-elastic properties and the neutron diffraction properties $[42,43]$. Here we observe that the antiferromagnetic transitio$\mathrm{n} \approx 52 \mathrm{~K}$ does not depend on the external applied fields, probably due to relatively strong antiferromagnetic forces [36]. Earlier, ZFC-FC that were done at much higher applied fields showed only Néel temperature with deviations in the ZFC-FC below $90 \mathrm{~K}[44,45]$.

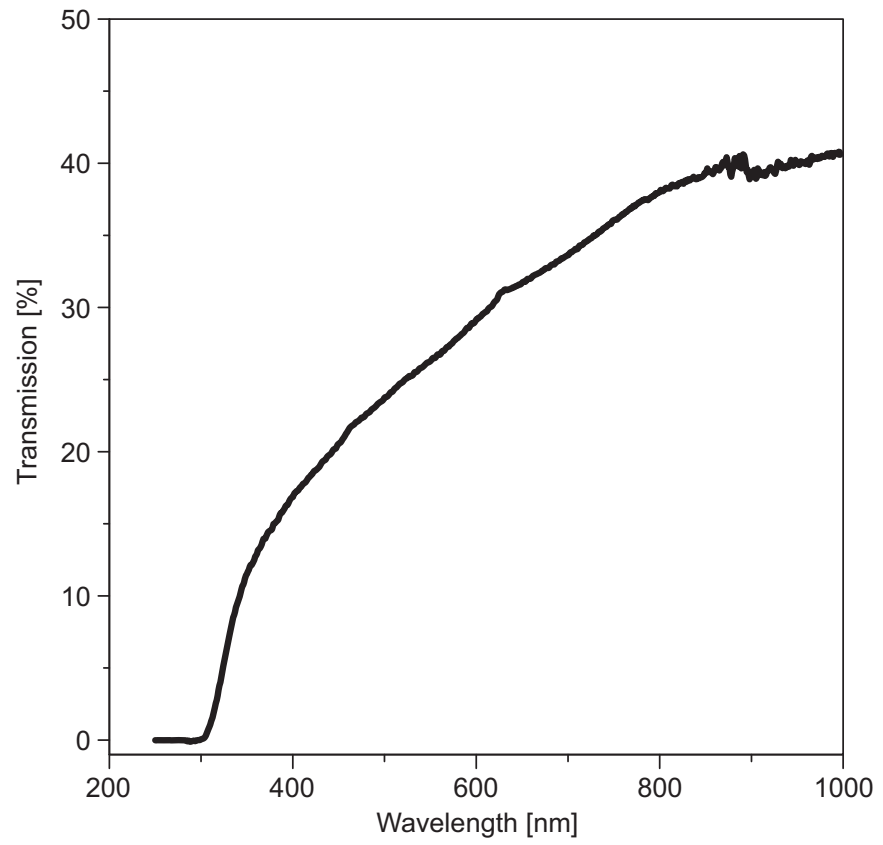

Fig. 4. Transmission spectra of $\mathrm{FeTiO}_{3}$ deposited on FTO glass substrate.

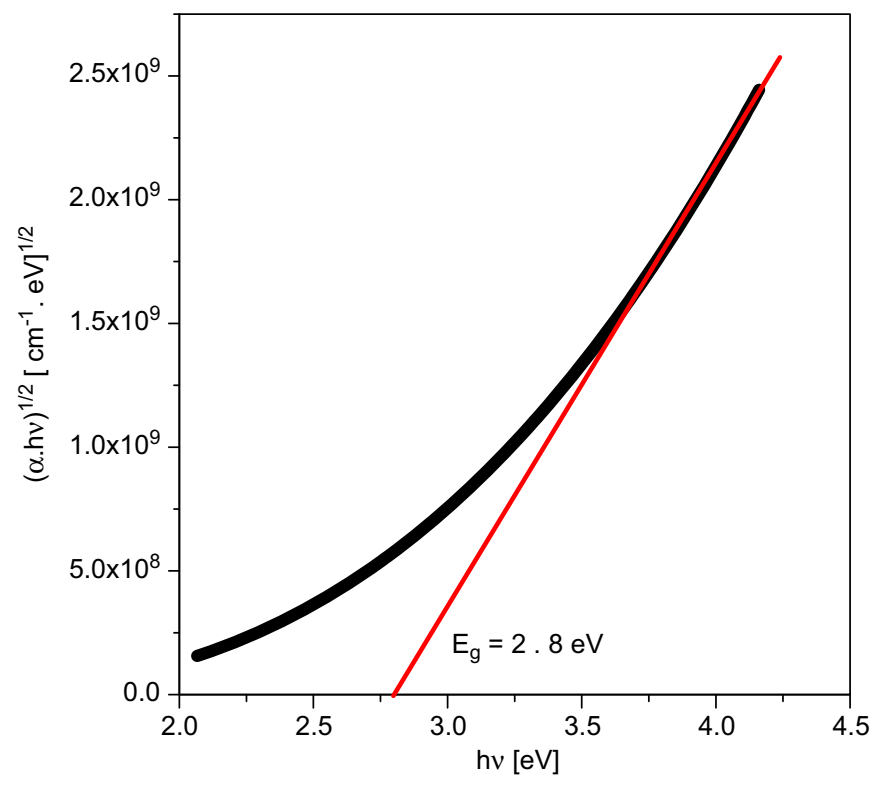

Fig. 5. Tauc plot of $\mathrm{FeTiO}_{3}$.

Hence, it is observed that the structural, optical and magnetic properties of $\mathrm{FeTiO}_{3}$ were found to be influenced by the nanoscaled structures.

\section{Conclusions}

Nano-ilmenite $\mathrm{FeTiO}_{3}$ have been successfully synthesized using sol-gel method. The bandgap of $\mathrm{FeTiO}_{3}$ was determined to be $2.8 \mathrm{eV}$. 


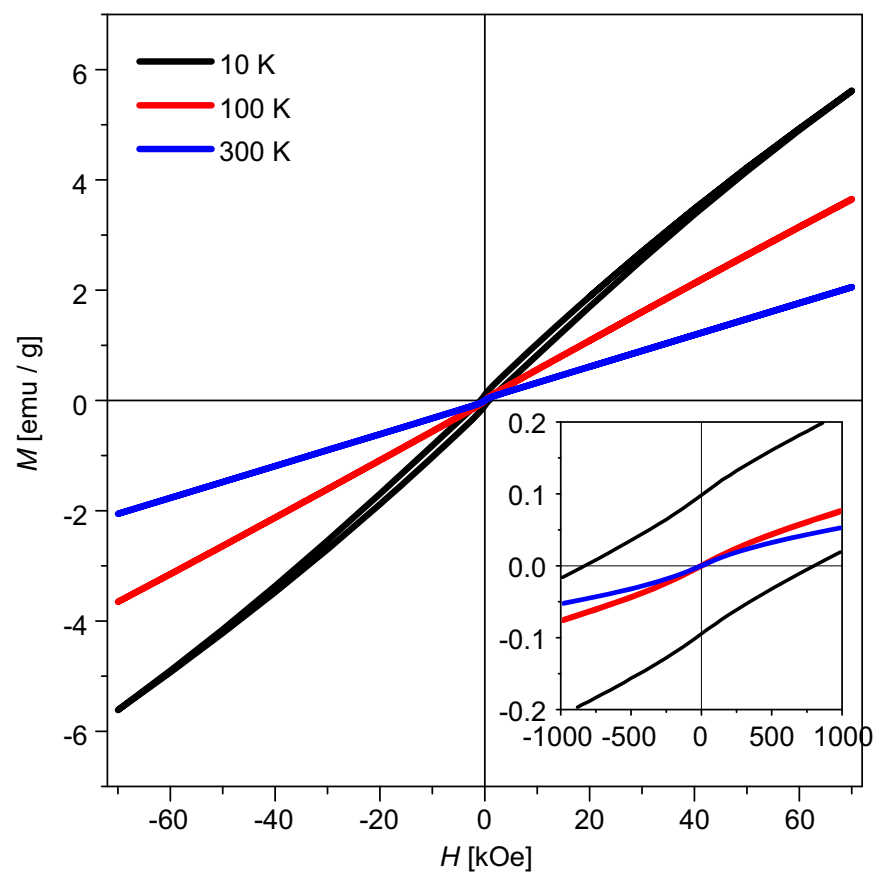

Fig. 6. Magnetization vs. magnetic field curve for nanocrystalline $\mathrm{FeTiO}_{3}$ powder. The inset shows the plot for magnetic field in expanded scale.

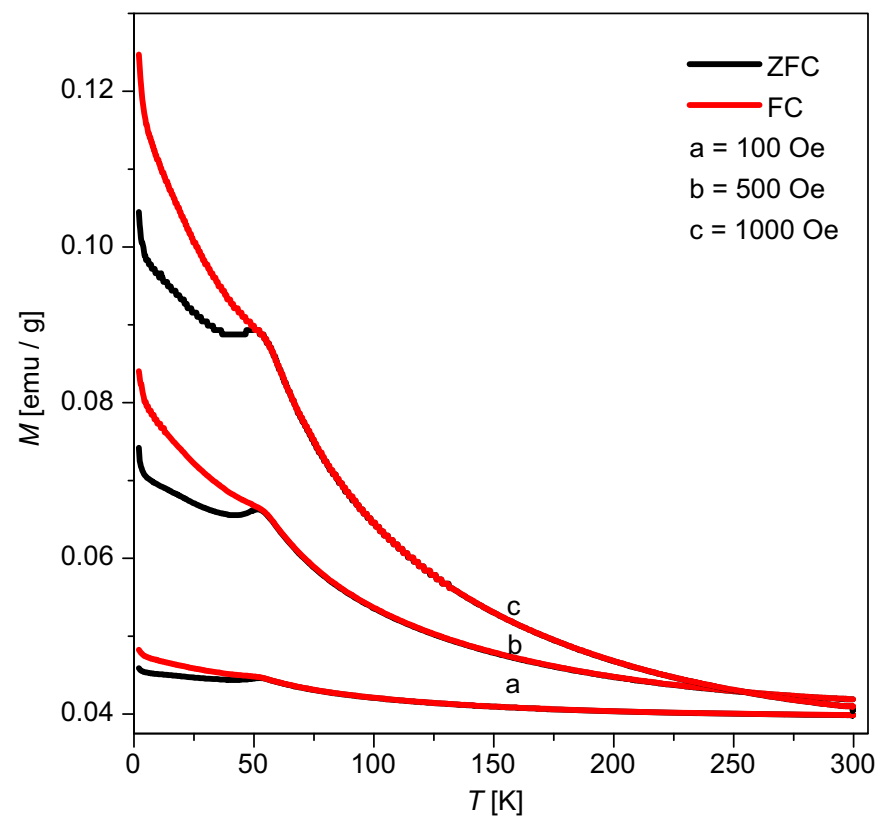

Fig. 7. Temperature dependent magnetization (ZFC-FC).

The synthesized $\mathrm{FeTiO}_{3}$ nanoparticles showed weak ferromagnetic properties at and below $300 \mathrm{~K}$. The $\mathrm{M}-\mathrm{H}$ curves measured for all the temperature range showed the weak ferromagnetism linked with the onset of the antiferromagnetic state. The antiferromagnetic (AFM) transition $T_{N} \approx 52 \mathrm{~K}$ was determined from the magnetization versus temperature data. The $T_{N}$ values are highly independent to the applied field further confirming the AFM nature of $\mathrm{FeTiO}_{3}$.

\section{Acknowledgments}

A.T.R would like to thank, BK21 Frontier Physics Research Division, Department of Physics and Astronomy, Seoul National University,
Seoul, South Korea, for the Postdoctoral fellowship and EU-FP program of NRF (National Research Foundation), South Korea for financial support. M.F.C and A.P.S. would like to thank the FCT (Fundação para a Ciência e Tecnologia) for funding and M.H.J. would like to thank KRF grant (2012-0004082) through the pluriannual contract with CFUM,Ciencia 2007 Program and the European Commission through FP7-PEOPLE-2010-IRSES-NanoCIS (269279).

\section{References}

[1] C. Frandsen, B.P. Burton, H.K. Rasmvssen, S.A. McEnroe, S. Morup, Physical Review B 8 (2010) 224423.

[2] T. Nagata, Nature 172 (1953) 850.

[3] Y. Ishikawa, S. Akimoto, Journal of the Physical Society of Japan 12 (1957) 1083.

[4] R.M. Bozorth, D.E. Walsh, A.J. Williams, Physical Review 108 (1957) 157

[5] P. Robinson, R.J. Harrison, S.A. McEnroe, R.B. Hargranes, Nature 418 (2002) 517.

[6] N.H. Butler, A. Bandopadhyay, R. Srinivasan, Journal of Applied Physics 93 (2003) 7882.

[7] S.E. Haggerty, V. Sautter, Science 248 (1990) 993.

[8] X. Tang, K. Hu, Journal of Materials Science 41 (2006) 8025.

[9] F. Ye, A. Ohmori, Surface and Coatings Technology 160 (2002) 62.

[10] T. Fujii, M. Kayano, Y. Takada, M. Nakanishi, J. Takada, Solid State Ionics 172 (2004) 289.

[11] Z. Dai, P. Zhu, S. Yamamoto, A. Miyashita, K. Narum, H. Naramoto, Thin Solid Films 339 (1) (1999) 11.

[12] F. Zhou, S. Kotru, R.K. Pandey, Materials Letters 57 (2003) 2104

[13] T. Dietl, H. Ohno, MRS Bulletin 28 (2003) 714.

[14] H. Yamada, Y. Ogawa, Y. Ishii, H. Sato, M. Kawasaki, H. Akoh, Y. Tokura, Science 305 (2004) 646.

[15] S. Kuroda, N. Nishizawa, K. Takita, M. Mitome, Y. Bando, K. Osuch, T. Dietl Nature Materials 6 (2007) 440.

[16] A.H. MacDonald, P. Schiffer, N. Samarth, Nature Materials 4 (2005) 195.

[17] F. Zhou, S. Kotru, R.K. Pandey, Thin Solid Films 408 (2002) 33.

[18] R. Pentcheva, H. Sadat Nabi, Physical Review B 77 (2008) 172405.

[19] P.F. McDonald, A. Parasiris, R.K. Pandey, B.L. Gries, W.P. Kirk, Journal of Applied Physics 69 (1991) 1104.

[20] T. Fujii, M. Kayaro, Y. Takada, M. Nakanishi, J. Takada, Journal of Magnetism and Magnetic Materials 272-276 (2004) 2010.

[21] C.H. Shomate, Journal of the American Chemical Society 68 (1946) 964.

[22] B.F. Naylor, O.A. Cook, Journal of the American Chemical Society 68 (1946) 1003

[23] R.W. Grant, R.M. Housley, S. Geller, Physical Review B 5 (1972) 1700.

[24] S. Ohara, K. Sato, Z. Tan, H. Shimoda, M. Ueda, T. Fukui, Journal of Alloys and Compounds 504 (2010) L17-L19.

[25] S. Ya, S. Ge, W. Qiao, Y. Zuo, Journal of Magnetism and Magnetic Materials 322 (2010) 824

[26] N.C. Wilson, J. Muscat, D. Mkhonto, P.E. Ngoepe, M.M. Harrison, Physical Review B 71 (2005) 075202.

[27] A.T. Raghavender, D. Pajić, K. Zadro, T. Mileković, P. Venkateshwar Rao, K.M. Jadhav, D. Ravinder, Journal of Magnetism and Magnetic Materials 316 (2007) 1.

[28] A.T. Raghavender, A.P. Samanthilleke, Pedro Sa, B.G. Almeida, M.I. Vasilevskiy, N.H. Hong, Materials Letters 69 (2012) 59.

[29] M. Olivares, M.C. Zuluaga, L.A. Ortega, X. Murelaga, A. Alonso-Olazabal, M. Urteaga, L. Amundaray, I. Alonso-Martin, N. Etxebarria, Journal of Raman Spectroscopy 41 (2010) 1543.

[30] L. Nodari, E. Marcuz, L. Maritan, C. Mazzoli, U. Russo, Journal of the European Ceramic Society 27 (2007) 4665.

[31] Y.K. Sharma, M. Kharkwal, S. Uma, R. Nagarajan, Polyhedron 28 (2009) 579.

[32] S.S. Sunkara, R.K. Pandey, Ceramic Transactions 60 (1995) 83.

[33] Z. Dai, H. Naramoto, K. Narumi, S. Yamamoto, A. Miyashita, Journal of Applied Physics 85 (1999) 7433.

[34] Y.H. Chen, Journal of Non-Crystalline Solids 357 (2011) 136.

[35] T. Varga, A. Kumar, E. Vlahos, S. Denev, M. Park, T. Sanehira, Y. Wang, C.J. Fennie, S.K. Streiffer, X. Ke, P. Schiffer, V. Gopalan, J.F. Mitchell, Physical Review B 103 (2009) 047601.

[36] R. Das, A. Jaiswal, S. Adyanthaya, P. Poddar, Journal of Physical Chemistry C 114 (2010) 12104.

37] X. Xu, A. Umezawa, G.W. Crabtree, Physical Review B 46 (1992) 11928

[38] V. Yu Galkin, W.A. Ortiz, E.J. Fawcett, Journal of Physics: Condensed Matter 9 (1997) L577.

[39] T. Katsufuji, S. Mori, M. Masaki, Y. Maritomo, N. Yamamoto, H. Takagi, Physical Review B 64 (2001) 419.

[40] H. Sadat Nabi, R.J. Harrison, R. Pentcheva, Physical Review B 81 (2010) 214432.

[41] Y. Endoh, Y. Ishikawa, H. Ohno, Journal of the Physical Society of Japan 24 (1968) 263.

[42] H.L. Alberts, J.A. Lourens, Journal of Physics F: Metal Physics 13 (1983) 873.

[43] L. He, C. Chen, N. Wang, W. Zhou, L. Guo, Journal of Applied Physics 102 (2007) 103911.

[44] K. Yoshii, H. Abe, Journal of Solid State Chemistry 165 (2002) 131.

[45] K. Uusi-Eko, J. Malm, N. Imamura, H. Yamamuchi, M. Karppinen, Materials Chemistry and Physics 112 (2008) 1029. 